\title{
Trabalho, trabalhadores e questão social na sociabilidade capitalista
}

\section{Reginaldo Guiraldelli ${ }^{1}$}

Este ensaio, por meio de revisão da literatura, analisa as transformações societárias em curso que afetam o mundo do trabalho e a vida em sociedade, provocando o acirramento da questão social, compreendida como resultante das contradições entre capital e trabalho. Em linhas gerais, tendo em vista o acúmulo de conhecimento produzido no campo das ciências sociais e humanas acerca do tema, são apresentados elementos acerca das alterações desencadeadas no mundo do trabalho e seus reflexos para os trabalhadores em tempos de crise do capital. Dentre as consequências dessas transformações estão a intensificação e a expansão de formas precárias de trabalho, o agravamento do pauperismo, o avanço do desemprego, a informalidade, as subcontratações, a miséria e a perda de direitos sociais. Tal quadro esboça, para o conjunto da classe trabalhadora, por meio de organizações e lutas coletivas, desafios com vistas à superação da sociabilidade capitalista.

Palavras-chave: Trabalho, Trabalhadores, Questão Social, Capitalismo.

Work, workers and the social issue in the capitalist sociability

This essay, through literature review, analyzes ongoing societal transformations affecting the world of work and life in society, besides provoking the worsening of the social issue, understood as resulting from the contradictions between capital and labor. Generally, taking into account the accumulation of knowledge produced in the field of social and human sciences on this subject, it is presented elements about the changes triggered in the world of work and its reflections to the workers in times of crisis of the capital. One of the consequences of these transformations are the intensification and the expansion of precarious forms of work, the increase of pauperism, the advancement of unemployment, informality, subcontracting, poverty and the loss of social rights. This framework outlines, for the whole working class, through organizations and collective struggles, challenges aimed at overcoming the capitalist sociability.

Keywords: Work, Workers, Social Issue, Capitalism.

\section{Questões introdutórias}

O presente ensaio, por meio de um balanço crítico bibliográfico da literatura especializada, objetiva apresentar reflexões acerca das transformações ocorridas nos últimos decênios no mundo do trabalho e seus impactos para os trabalhadores no capitalismo contemporâneo.

Em tempos históricos de crise do capitalismo financeiro em dimensão estrutural (Mészáros, 2009), profundas alterações no mundo do trabalho podem ser observadas, com queda no ritmo de crescimento, acentuados níveis de desemprego e miséria da população, o que contribui para o aprofundamento e agudização da questão social.

De acordo com Santos (2012), a questão social decorre das contradições e desigualdades sociais produzidas no capitalismo, caracterizadas por relações conflituosas e antagônicas entre capitalistas e trabalhadores. A questão social emerge na cena pública na primeira metade do século XIX, a partir da organização coletiva e luta dos trabalhadores reivindicando direitos de cidadania, assumindo assim, também uma dimensão política (Iamamoto, 2007). Vinculada à luta de classes e reconhecida suas contradições, a questão social envolve conformismo, resistência e rebeldia dos indivíduos sociais diante das formas de exploração e opressão vigentes na sociabilidade do capital. A partir de uma perspectiva de totalidade, a questão social precisa ser analisada com base no processo de acumulação e reprodução capitalista, pois,

1 Assistente Social, Mestre e Doutor em Serviço Social pela UNESP. Docente do Departamento de Serviço Social e do Programa de Pós-Graduação em Política Social da Universidade de Brasília (UnB). Coordena o Grupo de Estudos e Pesquisas sobre Trabalho, Sociabilidade e Serviço Social (GEPETSS). 
contraditoriamente, na medida em que a produção da riqueza é coletivizada, o seu resultado final é apropriado de maneira privada. Além do mais, a questão social assume particularidades e desdobramentos diversificados de acordo com a formação sócio-histórica regional e/ ou nacional (Ianni, 2004). Por ser a questão social expressão das contradições advindas da relação capital/trabalho, é importante analisar a morfologia do trabalho (Antunes, 2005) na sociabilidade capitalista como forma de decifrar as manifestações e o redimensionamento da questão social na contemporaneidade.

Assim, parte-se do entendimento de trabalho como categoria central e fundamental para a compreensão das relações sociais e da história da humanidade a partir de uma perspectiva ontológica. Na análise do trabalho é preciso apreender dimensões históricas e ontológicas na sua totalidade, com mediações e determinações, reconhecendo singularidades e universalidades.

Essa concepção precisa ser ressaltada tendo em vista que algumas abordagens sobre a realidade social, as transformações societárias e o mundo do trabalho têm enfatizado elementos metafísicos e empiricistas, desconsiderando as perspectivas ontológica e histórica e a totalidade social. Em muitos casos se enfatiza a imediaticidade, o efêmero e a fragmentação, o que corrobora para sustentar uma concepção de perenidade, triunfo e coroamento da sociabilidade burguesa. Análises conformistas, fatalistas e desistoricizadas da realidade social têm contribuído para disseminar a ideia do "fim da história", inspirada em Francis Fukuyama (1992), e do "fim do trabalho", inspirada em pensadores como André Gorz (1987), Domênico De Masi (2000), Jurgen Habermas (1987), Claus Offe (1994) e Jeremy Rifkin (1995). Nesse lastro, transmite-se uma ideia de que o atual estágio de sociabilidade, regido pela mercadoria, por relações mercantis e sustentado na propriedade privada e na divisão de classes, está determinado e não há qualquer alternativa ou forma de superação. Essa concepção ideológica burguesa, especialmente com a queda do Muro de Berlim em 1989, apregoa o ideário de que a ordem do capital é eterna e insuperável.

Nessa conjuntura, é necessário elucidar que, atualmente, o que se verifica é a redução de empregos estáveis e protegidos, o que não significa o "fim do trabalho" nem o "fim da história". $\mathrm{Na}$ atualidade, o que se observa é a eliminação de postos de trabalho, a redução de trabalho vivo e crescentes taxas de desemprego, que assume dimensão estrutural, ampliando o índice de trabalhadores supérfluos ao capital. Diferentemente do desemprego temporário e cíclico causado em períodos e conjunturas de crise do capital, o desemprego estrutural é caracterizado pela expulsão dos indivíduos da cadeia produtiva sem possibilidade de reinserção futura no mercado de trabalho, ou como diz Pochmann (2001, p. 89), é um "[...] desajuste entre a mão-de-obra demandada pelo processo de acumulação do capital e a mão-de-obra disponível no mercado de trabalho”.

Dessa forma, o trabalho não perdeu centralidade, como assinalado por Antunes (2007). O que se observa são mudanças nas formas de gerir e organizar os processos de produção na atual divisão internacional do trabalho. $\mathrm{O}$ trabalho permanece sendo o componente fundamental e estruturante da sociabilidade humana (Marx, 2006), em que homens/mulheres transcendem sua forma meramente biológica e constituem também uma natureza social, tornando-se seres sociais. Assim, o trabalho funda a sociabilidade humana. Por mais que os seres sociais tenham avançado no conhecimento e habilidades técnicas e científicas no domínio da natureza, não é possível haver vida social dissociada da vida natural, pois tanto a natureza social quanto a natureza biológica compõe a sociabilidade. Pelo trabalho, o homem se diferencia das demais espécies animais, tendo em vista sua capacidade teleológica, ou seja, sua ação consciente e projetiva. ${ }^{2}$ É pelo trabalho que o homem se constitui e realiza suas potencialidades humano-sociais, mas na sociabilidade regida

2 Marx faz essa distinção da seguinte forma: "Uma aranha executa operações semelhantes às do tecelão, e a abelha supera mais de um arquiteto ao construir sua colmeia. Mas o que distingue o pior arquiteto da melhor abelha é que ele figura na mente sua construção antes de transformá-la em realidade. No fim do processo do trabalho aparece um resultado que já existia antes idealmente na imaginação do trabalhador" (Marx, 2006, pp. 211-212). 
pelo capital, marcada pela mercantilização não só de bens, serviços e produtos, mas da própria vida humana, e pela exploração intensiva e extensiva da força de trabalho, verifica-se uma nova configuração das relações sociais e de trabalho, que passam a ser mediadas pela relação entre compradores e vendedores da força de trabalho. As relações sociais no capitalismo tornam-se coisificadas e alienadas, baseadas em relações de trocas, sem possibilidades de plena realização da liberdade. Heller (1985, p. 38) assinala que "Existe alienação quando ocorre um abismo entre o desenvolvimento humano-genérico e as possibilidades de desenvolvimento dos indivíduos humanos, entre a produção humano-genérica e a participação consciente do indivíduo nessa produção".

Na sociabilidade burguesa, o trabalho assume dimensão abstrata, alienada e fetichizada (Antunes, 1999), e se caracteriza pela produção de mercadorias e de mais-valia, com o objetivo de acumulação e reprodução ampliada do capital.

A partir de uma análise baseada na perspectiva materialista histórica e dialética, que exige fidelidade ao real e aos fenômenos emergentes do tempo presente, torna-se indispensável conhecer o mundo do trabalho na dinâmica da mundialização do capitalismo contemporâneo sob hegemonia financeira de forma a desvelar seus sentidos, significados e alterações substantivas que atingem indistintamente trabalhadores urbanos e rurais, homens e mulheres, brancos e negros, jovens, adultos e idosos.

Tendo em vista que a financeirização da economia adentra todos os meandros da vida social, a atual crise capitalista que se espraia por todos os hemisférios, territórios e formas de sociabilidade, não pode ser analisada de forma autonomizada, naturalizada, focalizada e desistoricizada, desconsiderando aspectos conjunturais e estruturais da realidade social. Os custos sociais da crise contemporânea têm recaído de forma avassaladora sobre a classe trabalhadora, diante do crescente desemprego, precarização das relações de trabalho, cortes e privatização dos serviços sociais públicos, violência, miserabilidade, repressão e criminalização dos movimentos sociais e populares.

Assim, o presente ensaio apresenta sumariamente algumas contradições, tensões e dilemas presentes na atual morfologia (Antunes, 2005) do mundo do trabalho em tempos de crise estrutural do capital (Mészáros, 2009), em que a classe trabalhadora convive com ameaças permanentes de desemprego e com políticas que atingem diretamente suas condições objetivas e subjetivas de vida e trabalho.

\section{Transformações no mundo do trabalho sob a regência do capital}

A terminologia "mundo do trabalho" adotada neste ensaio expressa os componentes sóciohistóricos caracterizados pelas diferentes formas sociais e técnicas de organizar, gerir e regular os processos produtivos na sociedade. Analisar as profundas alterações desencadeadas no mundo do trabalho na atualidade exige a apropriação de uma perspectiva histórica e ontológica, para que seja possível desvendar dialeticamente as contradições contemporâneas da sociedade burguesa, baseada no trabalho assalariado e na lógica de valorização e reprodução ampliada do capital.

3 "Todo trabalho é, de um lado, dispêndio de força humana de trabalho, no sentido fisiológico e, nessa qualidade de trabalho humano igual ou abstrato, cria o valor das mercadorias. Todo trabalho, por outro lado, é dispêndio de força humana de trabalho, sob forma especial, para um determinado fim, e, nessa qualidade de trabalho útil e concreto, produz valores-de-uso" (Marx, 2006, p. 68). Em suma, o trabalho concreto é produtor de valores de uso, ou seja, o resultado do trabalho humano tem utilidade para satisfazer as necessidades vitais da humanidade. Já o trabalho em sua dimensão abstrata, produz valores de troca, que é resultante da produção de mercadorias para atender à lógica da acumulação sob relações sociais capitalistas baseadas na compra e venda da força de trabalho. 
Desde a consolidação do capitalismo, com a Revolução Industrial do século XVIII iniciada na Inglaterra, os processos de trabalho assumiram novas formatações diante do fenômeno da industrialização e da urbanização. Nesse marco histórico, o capitalismo se consolidou e se desenvolveu pela lógica da livre concorrência, desencadeando concentração e centralização da produção, o que estimulou o surgimento de sua fase monopolista, também denominada imperialista, ou seja, um estágio superior do sistema produtor de mercadorias. Essa fase imperialista é compreendida como "[...] capacidade de mobilizar os recursos naturais e humanos [...] para fins políticos, econômicos e militares [...] um processo político-econômico difuso no espaço e no tempo no qual o domínio e o uso do capital assumem a primazia" (Harvey, 2009, p. 31).

Assim, o que sustenta a lógica imperialista do capitalismo é o seu processo acumulativo baseado na proteção da propriedade privada e no aumento do poder político, sempre pensados em escala expansiva de forma a garantir hegemonia e valorização do capital.

Como exemplo de um Estado imperialista, Harvey (2009, p. 40) menciona os Estados Unidos como potência hegemônica do mundo capitalista que se utiliza de coerção e consentimentos para manter seus interesses, negando irresponsavelmente a constituinte do país.

Nesse cenário, contraditoriamente, se propaga a ideia de uma era do capital marcada pelo avanço no campo técnico-científico, com crescimento e desenvolvimento econômico ao mesmo tempo em que se aprofunda a miséria, a violência, a exploração, a opressão, a xenofobia e a degradação do trabalho. Ou seja, a questão social, entendida como o conjunto dos antagonismos expressos na relação capital versus trabalho se manifesta com novos contornos, acirrando as desigualdades sociais.

Um exemplo elucidativo de exploração e degradação do trabalho na era do capital refere-se às condições precárias, insalubres e sub-humanas no ambiente fabril, com a incorporação de crianças e mulheres no decurso do século XIX. Tal inserção foi marcada por extensas jornadas, ambientes físico-estruturais insalubres, baixos salários, ausência de garantias legais e de proteção social.

No findar do século XIX, as atividades produtivas se complexificaram e, para tanto, tornou-se necessário sistematizar as operações, tanto na esfera da produção direta, quanto na administração e gerenciamento empresarial. Em busca de otimização nos padrões de produtividade, implantou-se o modelo taylorista, resultando em uma organização científica do trabalho. O engenheiro mecânico estadunidense Frederick Winslow Taylor (1856-1915), considerado o pai da Administração Científica do Trabalho, modificou o processo produtivo no momento em que separou concepção e execução no trabalho (Antunes, 2007). A partir de então, passou a ser competência da gerência o trabalho intelectual, enquanto que coube ao operário o trabalho manual. Outro princípio adotado por Taylor e incorporado na indústria da época consistiu em manter movimentos repetitivos e tarefas fragmentadas com rígido controle do tempo e rotinização, garantindo assim a relação de um trabalhador para uma máquina, o que implicava hierarquização e desqualificação no interior da produção. Conforme indaga Santana (2005, p. 6), zelava-se pela disciplina no ambiente laboral, enquanto a capacidade intelectiva dos trabalhadores era desprezada, visto que os mesmos eram adestrados pelos princípios da filosofia institucional.

Vale considerar que além de regular, controlar e dominar o ritmo de trabalho no espaço da produção, havia um forte controle da vida privada dos trabalhadores e, como exemplo disso, pode ser mencionada a criação das vilas operárias que serviam como estratégias coercitivas, consensuais e persuasivas para adentrar no universo privado dos trabalhadores e de seus familiares. Mas é importante ressaltar que, conforme salienta Hirata (2002, p. 32), o taylorismo não teve a mesma difusão, assimilação e repercussão no Brasil como em outros países, por exemplo a França e o Japão, tendo em vista as especificidades sócio-culturais, políticas, econômicas, geográficas e históricas de cada um. 
Em linhas gerais, o modelo de produção taylorista contribuiu para padronizar as formas de trabalho e uniformizar as operações, que foram incorporadas posteriormente pelo fordismo, modelo de produção adotado no início do século XX que teve como precursor o estadunidense Henry Ford (1863-1947). Em síntese, o fordismo se baseava na produção em massa. A produção seriada objetivava padronizar os produtos e reduzir o tempo e custo da produção, tendo em vista a fabricação em larga escala com a utilização de esteiras e de linhas de montagem.

Os avanços na automação, associados ao processo de "racionalização" do trabalho, representaram, de acordo com Antunes (1999; 2007), a intensificação do trabalho humano, caracterizado por esforços repetitivos em que os trabalhadores, limitados pelo tempo e pelas operações realizadas, tornaram-se apêndices do domínio das máquinas.

Tais modelos adotados na indústria no decorrer do século XX se caracterizaram pelo trabalho fragmentado e parcial, negando a criatividade, o saber e a capacidade intelectiva dos trabalhadores, que executavam somente determinadas operações do processo produtivo. Ou seja, os objetivos eram evidentes: simplificar, padronizar e uniformizar o trabalho (Santana, 2005). Outro elemento que merece destaque acerca dos modelos produtivos é que se buscava explorar e controlar de forma intensiva o trabalhador a fim de evitar manifestações individuais e/ou coletivas diante da emergência da questão social.

Também nessa fase era visível a desigualdade entre homens e mulheres no mundo do trabalho, pois, historicamente, as trabalhadoras sempre foram mais desvalorizadas, ocupando postos precários de trabalho e recebendo salários baixos. Diante disso, o que se observa é que a realidade atual não sofreu muitas variações, tendo em vista que as mulheres continuam predominantemente a ocupar postos de trabalho precarizados, com baixos rendimentos e intensas formas de exploração, perpetuando a divisão sexual do trabalho.

Os modelos de produção (taylorismo e fordismo) foram difundidos nas economias capitalistas centrais no decorrer das duas guerras mundiais e a eles se agregou o Estado de Bem-Estar Social, que emerge ao fim da Segunda Guerra Mundial.

Nesse período, as propostas elaboradas pelo economista britânico John Maynard Keynes (1883-1946) após a crise de 1929 foram implementadas em alguns países do hemisfério norte, o que representou a intervenção estatal no controle e na regulação econômica com a finalidade de garantir políticas sociais ao conjunto da população, redundando na formação do Estado de BemEstar Social. Harvey (2009) assinala que o keynesianismo, que deu base para a formação do Estado de Bem-Estar Social, teve vida efêmera, pois com a crise capitalista em meados dos anos 1970, o Estado passa a rever medidas que supostamente lhe geravam ônus e, assim, reduziu sua intervenção na esfera econômica e social. Isso resultou num processo de privatização do patrimônio público, transferindo os encargos e responsabilidades da gestão socioeconômica para o âmbito privado, acarretando uma fase regida pela lógica de mercado. Tal medida pode ser notada atualmente com as iniciativas privadas relacionadas ao acesso aos serviços e políticas sociais, ou seja, bens e direitos que outrora eram garantidos pela esfera pública, passam a ser adquiridos e acessados pela via do mercado.

Nesse lastro temporal, com base nos apontamentos de Sorj: “[...] até os anos 70, nas sociedades avançadas, o chamado 'emprego em tempo integral e para a vida toda' era uma forte referência tanto no planejamento organizacional das empresas como no horizonte existencial dos trabalhadores" (2000, p. 31).

Entretanto, o Estado de Bem-Estar Social e o padrão fordista de produzir dão sinais de saturação e passam a ser repensados no decorrer dos anos 1970. Nesse período, alguns acontecimentos contribuíram para engendrar um clima de instabilidade econômica frente à elevação dos preços do petróleo ditado pela Organização dos Países Exportadores de Petróleo (OPEP) em 1973 e, posteriormente, em 1979, bem como a sucessiva valorização e desvalorização do dólar, oscilando 
as taxas de câmbio. Conforme sustenta Harvey (2009, p. 57), o crescente custo com o conflito militar no Vietnã também resultou em uma crise fiscal do Estado com fortes pressões inflacionárias em âmbito mundial, deflagrando uma onda de falências graças à explosão de capital "fictício" em circulação, além dos elevados gastos sociais. Emerge uma crise de sobreacumulação do capital, ${ }^{4}$ sendo essas tendências intrínsecas ao próprio sistema produtor de mercadorias, colocando em colapso o sistema financeiro de Bretton Woods nos anos 1970. ${ }^{5}$

Nesse contexto, algumas medidas foram tomadas a fim de garantir a preservação e reprodução da ordem acumulativa do capital e, dentre tais estratégias, Anderson (2008) aponta o neoliberalismo, originado após a Segunda Guerra Mundial como reação teórica e política ao Estado de Bem-Estar Social. Um dos idealizadores de maior expressão no advento do receituário neoliberal foi o economista austríaco Friedrich von Hayek (1899-1992), com sua obra O caminho da servidão, elaborada no ano de 1944. Sua finalidade era a derrocada do keynesianismo e a extinção de regras para o mercado. Porém, seguindo a análise de Anderson (2008), naquela época, o capitalismo desfrutava de sua fase áurea, o que impossibilitava a adoção das medidas acenadas pelos adeptos do neoliberalismo. Na década de 1970, porém, a crise atinge um profundo quadro de recessão, elevadas taxas inflacionárias e redução do crescimento econômico, momento em que as ideias neoliberais passam a ganhar terreno.

Nas elucidações de Anderson (2008), o neoliberalismo se expande, ganhando adesão, o que se pode notar com a eleição de Margaret Thatcher, em 1979, na Inglaterra e, em seguida, no ano de 1980, com Ronald Reagan, outro ícone simpatizante dos preceitos neoliberais, eleito presidente dos Estados Unidos. Assim, tal movimento foi ganhando visibilidade e se alastrando por inúmeros países da Europa e América do Norte. Os demais países que não incorporaram inicialmente os ditames do receituário neoliberal foram aos poucos sendo obrigados a se adequar às normas propagadas, seguindo as tendências e leis do mercado mundial. Com isso, o Estado passou a transferir suas responsabilidades para o mercado, pois em síntese, o neoliberalismo prevê uma intervenção mínima do Estado no que tange aos serviços sociais públicos e uma intervenção máxima no mercado capitalista sob a hegemonia financeira.

A crise capitalista nos anos 1970 também propiciou o surgimento de outras formas de gestão e organização do trabalho, conforme se observou na "Terceira Itália" e no Japão com a incorporação do modelo de produção toyotista, baseado no sistema just-in-time, kanban e de "células de produção", ou seja, na filosofia de uma empresa "enxuta" e flexível (Antunes, 1999)?.

4 "A sobreacumulação [...] é uma condição em que excedentes de capital (por vezes acompanhados de excedentes de trabalho) estão ociosos sem ter em vista escoadouros lucrativos. O termo-chave aqui é, no entanto, excedentes de capital" (Harvey, 2009, p. 124).

5 Instaurado na década de 1940, o Acordo de Bretton Woods representava a hegemonia norte-americana, passando o dólar a ser a moeda de referência e, com isso, objetivava "[...] estabilizar o sistema financeiro mundial, o que se fez acompanhar por toda uma bateria de instituições, como o Banco Mundial, o FMI, o Banco Internacional de Compensações, na Basiléia, e da formação de organizações como o GATT [Acordo Geral de Tarifas e Comércio] e a OCDE [Organização para Cooperação e Desenvolvimento Econômico], projetadas para coordenar o crescimento econômico entre as potências capitalistas avançadas e levar o desenvolvimento econômico de estilo capitalista ao resto do mundo não-comunista. [...] os Estados Unidos eram não só dominantes como hegemônicos, no sentido de sua posição como Estado superimperialista [...]” (Harvey, 2009, p. 52).

6 A partir dos anos 1970 (Pinto, 2007), a economia italiana engendrou um acentuado dinamismo para a economia do país, formando distritos industriais. No caso da Terceira Itália, que envolve Vêneto, Emilia-Romana, Marcas e Toscana, instalou-se pequenas e médias empresas em áreas de tradição artesanal, com alta capacidade de inovação e flexibilização das relações de trabalho.

7 A experiência toyotista foi desenvolvida na empresa japonesa Toyota Motor Company nos anos 1950, pelo engenheiro industrial japonês Taiichi Ohno (por isso tal modelo é também conhecido por ohnismo) logo após o fim da Segunda Guerra Mundial e representou alterações substantivas na organização e na gestão dos processos produtivos. "[...] just-in-time significa produzir somente o que é necessário, [...] na quantidade necessária [...] e no momento necessário" (Pinto, 2007, p. 83), ou seja, com a finalidade de redução da estocagem. Já o kanban significa "[...] esses fluxos de informação e de materiais foram possibilitados pela elaboração de um dispositivo mecânico que conduzia caixas no sentido inverso da produção [...] contendo cartazes [...] com informações sobre a quantidade necessária de alimentação dos postos subsequentes, ao mesmo tempo em que outras caixas passaram a circular no sentido normal do fluxo produtivo [...], carregadas das peças ou materiais encomendados por cada um desses postos" (Pinto, 2007, pp. 78-79). As células de produção "[...] constituem-se de equipes de trabalhadores, que podem alternar-se em seus postos conforme o volume de produção pedido ou metas de qualidade exigidas ou outro motivo" (Pinto, 2007, p. 80). Os trabalhadores passam a ser controlados e supervisionados pelos próprios integrantes da equipe em prol do cumprimento das metas empresariais. 
Também surgiram os Círculos de Controle de Qualidade (CCQs) com o intuito de agrupar os trabalhadores para discutirem não só a qualidade do trabalho realizado mas, principalmente, de gerar um sentimento de "pertencimento" à empresa. Nessa fase, conforme alerta Antunes (1999), o capital apropriou-se do savoir faire intelectual do trabalhador.

Nesse sentido, o toyotismo, conforme sublinha Alves (2005, pp. 30-33), captura a subjetividade dos trabalhadores e não rompe, necessariamente, com a base taylorista/fordista. O toyotismo surge para atender às necessidades de acumulação, reprodução e valorização do capital em um período de crise de superprodução. Assim, o toyotismo é um processo de continuidade e descontinuidade com os modelos taylorista e fordista, ou seja, “[...] dá continuidade à lógica de racionalização do trabalho na perspectiva da hegemonia do capital na produção" (Alves, 2005, p. 39).

Essa fase, também denominada por Harvey (1998) de acumulaçãoflexível, exige um trabalhador polivalente/multifuncional, ou seja, que possa dispor de todas as suas potencialidades humanas, tanto no que tange às necessidades operacionais e executoras da instituição empregadora, quanto para pensar e conceber os processos de trabalho. Com isso, se observa que o capital, em sua dimensão destrutiva, apropria-se de forma predatória e intensificada do intelecto e da força física do trabalho humano. ${ }^{8}$

Também foram implantados os sistemas de Desenho Assistido por Computador (CAD) e de Manufatura Assistida por Computador (CAM), externalizando parte da produção industrial e, com isso, desempregando grandes contingentes de trabalhadores.

Outro elemento incorporado pelo modelo toyotista foi o sindicalismo de envolvimento "por empresa" (Santana, 2005), que se alia ao capital com o intuito de atender aos requisitos corporativos do sistema produtor de mercadorias, demonstrando a fragilização dos movimentos operários à época.

No bojo desse movimento sustenta-se um ideário de competência dos trabalhadores como resposta para atender aos interesses e às necessidades do capital, que se preocupa com resultados e não com processos. Na análise de Santana (2005, pp. 11-12), com o discurso da competência e a exigência de qualificação dos trabalhadores, cria-se o conceito de empregabilidade, que consiste na capacidade da força de trabalho se manter empregada ou encontrar novos empregos, o que, resumidamente, significa tornar-se empregável no mundo do trabalho mediante as atitudes e as competências dos trabalhadores. Nesse sentido, muitos trabalhadores tornam-se supérfluos e desnecessários ao capital, e o desemprego passa a ser justificado pela ausência de qualificação da população frente às exigências do paradigma produtivo vigente. $\mathrm{O}$ desemprego, compreendido como expressão da questão social, ou seja, um fenômeno social que tem dimensão pública e política, passa a ser tratado, muitas vezes, como um problema individual.

O que se verifica é um discurso ideológico emanado pelos setores dominantes para sustentar o atual quadro de desemprego, provocando a culpabilização dos trabalhadores pela situação vivenciada, pois mesmo com a expansão de cursos tecnológicos, profissionalizantes, especializações, treinamentos e diversos investimentos feitos em busca da qualificação profissional, nota-se que o quadro de desemprego continua alarmante, não sendo legitimada a ideia de educação como panaceia para a resolução dos males engendrados pelo mundo do trabalho em tempos de crise do capital. Como analisado por Marx (2006), o exército industrial de reserva, composto por sobrantes

Um dos principais lemas defendidos no interior desse modelo é a lealdade dos trabalhadores, ou seja, todos unidos devem zelar pelos interesses da empresa.

8 No modelo toyotista foi desenvolvida a concepção de "autonomação", que significa a "[...] junção das palavras autonomia e automação. É um princípio ‘importado’ por Ohno da indústria têxtil, na qual um só operário executava o trabalho em quarenta máquinas ao mesmo tempo" (Alves, 2005, p. 43). Com isso, verifica-se que no sistema Toyota um novo perfil de trabalhador é incorporado, o multifuncional, diferente do trabalhador da fase taylorista/fordista que se caracterizava pela relação um homem/ uma máquina. 
e desempregados, é funcional ao processo de reprodução e acumulação capitalista, que se perpetua pela existência do excedente, ou seja, é necessária a manutenção de uma reserva de trabalhadores fora do mundo do trabalho para que o capitalismo permaneça vivo e continue ditando suas regras.

Nessa conjuntura, "Empregos permanentes estão cada vez mais restritos. [...] Os novos postos criados tendem a ser flexíveis no tempo, no espaço e na duração, dando origem a uma pluralidade de contratos de trabalho: em tempo parcial, temporários ou por conta própria" (Sorj, 2000, p. 31).

Desde os anos 1970, as mudanças em curso nas formas de organizar, gerir e regular o trabalho foram implantadas pelos diversos territórios e continentes de forma desigual, trazendo incidências diferenciadas nas formas de contratação e nas exigências postas pelo mercado acerca da qualificação dos indivíduos que vivem da venda da força de trabalho.

Considerando os incrementos e avanços no campo tecnológico e científico, as distâncias espaciais foram reduzidas, o que propiciou a propagação de multinacionais e a formação de arranjos e distritos industriais, como citado pela experiência da Terceira Itália e da Toyota, no Japão. Nesses novos tempos, o modelo de produção japonês, ou seja, o toyotismo, passou a ser considerado a alternativa ideal para o mundo do trabalho diante do quadro anterior de falta de competitividade e dificuldade em controlar e disciplinar a força de trabalho.

A "qualidade total" e o just-in-time passaram a ser os princípios regentes da filosofia empresarial e, diante da adesão à lógica de acumulação produtiva, verifica-se a redução de custos sociais, com ênfase na desvalorização da força de trabalho, trazendo sérias consequências para os níveis de emprego. A instabilidade, a insegurança e a incerteza no trabalho também passaram a compor o cotidiano dos trabalhadores que ainda possuem um tipo de atividade remunerada, o que provoca a fragilização de instâncias representativas dos trabalhadores, como é o caso dos sindicatos, que "[...] são formas, entre outras, de representação de assalariados, já que estes se reconhecem também dentro de movimentos sociais, pequenos grupos de esquerda, de partidos de esquerda, partidos de direita e às vezes de extrema direita, presentes no mesmo lugar de trabalho" (Ramalho \& Santana, 2003, p. 25). Para os autores, se as principais bandeiras reivindicativas do sindicato na década de 1980 estavam vinculadas às questões de ordem econômica e salarial, na década de 1990 as principais problemáticas se consistiam na garantia do emprego e no combate ao desemprego. Os autores atestam que o grande desafio do sindicalismo na atualidade consiste na preservação de empregos e no respeito aos direitos de cidadania e, para isso, o sindicato precisa se articular "[...] a outros movimentos sociais com o objetivo de ampliar a base de atuação política em defesa de direitos do trabalho e de cidadania" (Ramalho \& Santana, 2003, p. 35).

$\mathrm{Na}$ atualidade, o sindicalismo apresenta, contraditoriamente, momentos de refluxo do seu movimento, fruto de uma crise do sistema metabólico do capital que pode ser superada. Por isso, não se pode considerar tal recuo como uma decadência ou falência dos sindicatos, pois a questão social, nos dizeres de Iamamoto (2007), conjuga momentos de rebeldia e resistência com momentos de conformismo, tendo em vista interesses sociais distintos. A partir de uma perspectiva histórica e dialética, tal quadro não é estanque e, sendo assim, pode ser reversível.

Tendo em vista as alterações substantivas no mundo do trabalho que incidem na degradação das condições de vida da população, é importante destacar que esse processo, também conhecido por reestruturação produtiva, ${ }^{10}$ se expande no contexto de mundialização do capital, ${ }^{11}$ que segundo

9 Qualidade total significa reduzir a vida útil dos produtos com o propósito de intensificar o ciclo reprodutivo do capital, ou seja, os produtos precisam ser rapidamente substituídos (Antunes, 2005).

10 Para Ramalho e Santana (2003, p. 14), a reestruturação produtiva indica “[...] um conjunto importante de mudanças, mas também considerando que essas mudanças adquirem formatos diferentes a partir das diversas realidades, histórias e conjunturas às quais estão associadas".

11 Chesnais (1996, pp. 23-25) traz a discussão da mundialização em contraposição à globalização, considerada para o autor como um processo que defende tal movimento como irreversível, benéfico e necessário. O autor elucida que o adjetivo "global" foi originado

\section{8}


Chesnais (1996, p. 13), representa uma nova fase de configuração do capitalismo mundial. Esse processo deve ser compreendido como uma etapa específica de internacionalização e valorização do capital. A impressão é de que, nessa fase, o capitalismo triunfou e pareceu dominar todos os continentes. Para o autor, situar a mundialização ao conceito de capital significa se remeter aos anos 1979-1981, quando, por meio de estratégias políticas e ideológicas, alguns Estados-Nação incorporaram o receituário neoliberal e passaram a ter liberdade de fluxo e circulação nos países que atendessem a seus interesses. $O$ resultado disso foi a implementação de "[...] políticas de liberalização, de privatização, de desregulamentação e de desmantelamento de conquistas sociais e democráticas" (Chesnais, 1996, p. 34).

A ascensão do capital financeiro com o objetivo de aumentar a produtividade do capital e do trabalho provocou consequências deletérias para o mundo do trabalho, principalmente no que concerne ao crescimento exponencial do desemprego. Não obstante, os princípios da empresa "enxuta", pautados no modelo japonês (toyotista/ohnista), os processos de terceirização e a precarização nas relações contratuais ganharam fôlego no quadro de ascensão do capital financeiro, e as multinacionais passaram a buscar locais de produção com baixos salários de forma a intensificar o trabalho e manter relações de trabalho pautadas na flexibilização. Com isso, "As legislações em torno do emprego do trabalho assalariado, que haviam sido estabelecidas graças às grandes lutas sociais e às ameaças de revolução social, voaram pelos ares [...]" (Chesnais, 1996, p. 42).

O processo de reestruturação produtiva, com marco temporal de sua aceleração nos anos de 1970, teve repercussão brusca para o conjunto dos trabalhadores, visto que representou incremento tecnológico e científico nos processos de trabalho, propiciando novas formas de organizar, gerir e regular a produção e a força de trabalho.

Segundo denominação de Alves (2005, p. 11), o "novo complexo de reestruturação produtiva" surge sob os auspícios do processo de mundialização do capital e envolve inovação tecnológica, científica e organizacional com o surgimento da robótica, microeletrônica, modalidades de gestão do trabalho pautadas nos programas de qualidade total e nos Círculos de Controle de Qualidade (CCQs), reengenharia, centralização e concentração de capitais, descentralização produtiva diante de relocalizações espaciais/territoriais das indústrias, terceirização e a adoção de uma legislação trabalhista de cunho flexível.

Nas reflexões de Alves (2005, p. 103), o Brasil vivenciou três fases de reestruturação produtiva, sendo a primeira desdobrada nos anos 1950, no governo de Juscelino Kubitschek (1956-1961), com o surgimento da grande indústria de base taylorista-fordista. A seguir, o outro momento da reestruturação produtiva se deu no período do "milagre econômico", ou seja, em plena ditadura militar, na década de 1970. Por fim, a terceira e atual fase ocorre em tempos de crise do capitalismo brasileiro, gestado nos anos 1980 e que se estendeu pelos anos 1990 e pela primeira década do século XXI, sob o ideário neoliberal. O autor denomina esse último estágio de reestruturação produtiva de "novo complexo" por abarcar a fase de acumulação flexível no contexto da Terceira Revolução Tecnológica.

Na década de 1990, sob a chancela do Consenso de Washington, ${ }^{12}$ o Brasil aderiu às prerrogativas neoliberais como alternativa de recuperação do capital. Com o neoliberalismo e

nos anos 1980 nas escolas americanas de administração de empresas. A partir dessa concepção, a nomenclatura globalização pode escamotear os ardis ideológicos e políticos apregoados pela lógica do capital sob os auspícios do neoliberalismo.

12 "Em novembro de 1989, reuniram-se na capital dos Estados Unidos funcionários do governo norte-americano e dos organismos financeiros internacionais ali sediados - FMI, Banco Mundial e BID - especializados em assuntos latino-americanos. O objetivo do encontro [...] era proceder a uma avaliação das reformas econômicas empreendidas nos países da região. Para relatar a experiência de seus países também estiveram presentes diversos economistas latino-americanos. As conclusões dessa reunião é que se daria, subsequentemente, a denominação informal de 'Consenso de Washington”' (Batista, 2001, p. 11). O Brasil aderiu aos requisitos do Consenso de Washington no período do governo Fernando Afonso Collor de Mello (1990-1992), quando, no intuito de solucionar 
a incorporação da reestruturação produtiva desencadeada pelas transformações no mundo do trabalho, o que se observou foi uma reforma do Estado, resultando na desregulamentação do trabalho, flexibilização das leis trabalhistas, reforma previdenciária e perda do poder de barganha do sindicalismo. Ao contrário do que ocorreu nas décadas de 1950 e 1960, com investimentos produtivos visando a geração de empregos industriais, nos anos 1990, o investimento consistiu em garantir intensivamente o processo acumulativo e reprodutivo do capital. Em contraposição à Constituição Federal de 1988, que representava conquistas históricas no campo da garantia dos direitos sociais, políticos, humanos e civis, o país incorporou a política neoliberal que gerou efeitos perversos para a vida social dos trabalhadores.

Com a abertura comercial adotada pelo Governo Collor nos anos 1990, a indústria brasileira atravessou períodos nebulosos e críticos diante das adversidades econômicas, políticas e sociais da época. O resultado disso foi um período de recessão, crescente desemprego e falência de indústrias que não estavam preparadas para a concorrência externa.

Diante da expressiva redução do emprego no ramo industrial nesse período, Lavinas (2000, p. 140) salienta que os mais atingidos pelo desemprego foram os homens, sendo que até então esses eram os ocupantes majoritários do setor, diferente do comércio, em que a taxa de desemprego feminino foi superior à masculina por ser um setor com maior contingente de mulheres.

$\mathrm{Na}$ década de 1990 ocorreu um redimensionamento da questão social, gerado pela trágica ofensiva neoliberal no contexto da reestruturação produtiva e da exploração "selvagem" dos trabalhadores. O neoliberalismo, caracterizado pela privatização do patrimônio público, flexibilização das relações de trabalho e desregulamentação das relações comerciais, eliminou as barreiras alfandegárias, oferecendo ao capital livre trânsito pelas economias mundiais e provocando a competitividade entre os mercados.

Além do mais, o projeto ideopolítico neoliberal aprofundou a questão social e suas múltiplas refrações são visíveis, como: a crescente violência urbana e rural, a pauperização e a miserabilidade da população, o desemprego estrutural, a informalidade, a flexibilização e a precariedade das relações de trabalho, a degradação ambiental, o racismo, o sexismo, a homofobia, a intolerância étnica e religiosa, a xenofobia, a segregação territorial, a repressão e criminalização dos movimentos sociais, os cortes e a privatização dos serviços sociais públicos (como a saúde, a educação, a cultura, a previdência social e a assistência social), alargando e agudizando as desigualdades sociais inerentes ao capitalismo.

No cerne da reestruturação produtiva e do neoliberalismo, as formas flexíveis e a terceirização nas relações de trabalho, redimensionam os processos produtivos e, como estratégia adotada pelo capital para reduzir custos, contribuem para fragmentar e fragilizar a organização coletiva dos trabalhadores, ou seja, reduz ou até mesmo elimina formas de enfrentamento e resistência dos trabalhadores que muitas vezes se encontram pulverizados.

Nesse atual estágio acumulativo do capital, se conjuga o advento de um precário mundo do trabalho com uma crise do sindicalismo brasileiro (Alves, 2005, p. 101), que se encontra enfraquecido e fragilizado perante a perversidade da ordem capitalista. ${ }^{13}$ Para Ramalho e Santana (2003, p. 26), um dos fatores que leva à desmobilização do sindicalismo está relacionado ao fenômeno do desemprego, que passa a gerar medo, insegurança e incertezas para aqueles que ainda se encontram em situações de "conforto" e estabilidade no mundo do trabalho.

a inflação, foram adotadas medidas que propiciaram uma onda de crises e privatizações, as quais contribuíram para seu processo de impeachment.

13 "Isto é feito sob a ameaça do desemprego, com o apoio das novas teorias e políticas governamentais em matéria de salário e de emprego, e também com o consentimento de dirigentes sindicais que julgam que 'não há alternativa” (Chesnais, 1996, p. 131). 
Ao mesmo tempo, como forma de pressionar e questionar tal realidade, organizações coletivas de trabalhadores emergem na cena pública pressionando o Estado e o empresariado de forma a reivindicar direitos e reconhecimento de cidadania. Como exemplo, cabe mencionar o caso emblemático dos metalúrgicos do ABC paulista nos anos 1970, as históricas greves gerais, as mobilizações dos movimentos sociais e demais ações e lutas coletivas de trabalhadores em âmbito nacional e internacional, que têm provocado a necessidade de revisão das políticas implementadas sob a ótica do receituário neoliberal. Dentre as inúmeras formas de resistência, mobilização e lutas coletivas da contemporaneidade, verifica-se um estado de efervescência e inquietação social que se alastra pelo cenário mundial e brasileiro, como é o caso dos Piqueteiros na Argentina, do Occupy Wall Street e das manifestações ocorridas em junho de 2013 no Brasil, que

[...] mudaram a face e o cotidiano de nossas cidades [...]. Pela rapidez com que se espraiaram, pelas multidões que mobilizam, pela diversidade de tema e problemas postos pelos manifestantes, elas evocam os grandes e raros momentos da história em que mudanças e rupturas que pareciam inimagináveis até a véspera se impõem à agenda política da sociedade e, em alguns casos, acabem transformando em possibilidade algumas mudanças sociais e políticas que pareciam inalcançáveis (Vainer, 2013, p. 35).

Diante dessa realidade complexa, dinâmica, tensa e contraditória, o cenário contemporâneo, caracterizado pela erosão dos direitos sociais, esboça inúmeros dilemas e desafios para as ações coletivas e para as lutas sociais da classe trabalhadora. As organizações sindicais permanecem vivas e acumulam contribuições e conquistas históricas de suma importância para os trabalhadores, mas as adversidades da conjuntura atual exigem do sindicalismo a busca de alianças e articulações para além dos espaços institucionais e profissionais como estratégia de assegurar seu viés combativo. Por isso, com base em Ramalho e Santana (2003), os sindicatos precisam rever ações pontuais, fragmentadas, corporativas e emergenciais, estabelecendo alianças com os movimentos sociais e populares, partidos de esquerda e entidades da sociedade civil no sentido de fortalecer as lutas políticas anticapitalistas, em defesa dos direitos sociais da classe trabalhadora, tendo como horizonte uma sociedade emancipada. Isso significa reafirmar a perspectiva da luta de classes, reconhecendo a classe trabalhadora como protagonista das transformações sócio-históricas.

Sendo assim, é importante considerar que pensar estratégias e alternativas de organização coletiva dos trabalhadores pode engendrar riscos ao adotar, criar ou incorporar modelos preestabelecidos e determinados, como se fosse possível encaixar uma proposta na dinamicidade do real. Por isso, para evitar análises e propostas simplistas, baseadas em fatalismo, pragmatismo, esquematismo e messianismo, reproduzindo a concepção de desencantamento do mundo, é indispensável problematizar dialeticamente essa realidade. Para tanto, as estratégias e alternativas de pressão, organização e mobilização dos trabalhadores devem estar sintonizadas com as demandas do tempo presente, considerando que o neoliberalismo e a reestruturação produtiva não são fatalidades insuperáveis.

\section{Reestruturação produtiva e neoliberalismo: consequências para os trabalhadores}

No âmago da mundialização do capital, ou seja, de uma organização social em que o capital financeiro circula desenfreadamente por todos os pontos dos hemisférios em busca de lucratividade e de predomínio da reestruturação produtiva e da lógica neoliberal, as atividades produtivas 
são deslocadas para diversas regiões geográficas e territórios, tendo como premissa a busca por localidades com baixos salários para a manutenção da força de trabalho, escassos direitos sociais e reduzida capacidade organizativa dos trabalhadores.

Nesse cenário, a produção é regulada pelo avanço tecnológico e científico em que o trabalho morto substitui o trabalho vivo, ou seja, substitui-se a força humana de trabalho por maquinário. Além disso, as empresas adquirem certa elasticidade para deslocarem sua produção para outros territórios, operando de forma global e se beneficiando de níveis salariais inferiores, da ausência de organização coletiva dos trabalhadores e de estímulos fiscais. Outros fatores que merecem ser destacados são o crescente desemprego, o aumento do emprego "autônomo", informal, temporário, domiciliar e subcontratado, além de um conjunto de arranjos produtivos que provocam consequências deletérias para a vida dos trabalhadores. Para Ramalho e Santana (2003, p. 19), a informalidade não contribuiu para minimizar ou reduzir a exploração no trabalho mas, ao contrário, serviu para combinar flexibilidade, exploração, abuso, produtividade e desproteção social.

Em relação a tais transformações, Sorj (2000, p. 29) assinala que, nesse cenário, o setor de serviços tem crescido de forma expressiva como os transportes, comunicação, administração, educação, saúde e finanças, em detrimento de uma queda da participação das indústrias.

Tal fato pode ser demonstrado no caso do trabalho bancário e da indústria automobilística que geraram uma redução significativa do contingente de trabalhadores, pois, a reestruturação produtiva tem provocado consequências nefastas tanto no âmbito da indústria e dos serviços, quanto na agricultura, onde o processo de mecanização no campo tem desencadeado um alto índice de desemprego, expulsão de trabalhadores rurais e miserabilidade. Vale lembrar também dos elevados índices de acidentes e mortes de trabalhadores rurais em decorrência da alta carga de exploração, intensificação e fadiga no trabalho, como é o caso das atividades no setor canavieiro.

Por isso, no cerne da mundialização e financeirização do capital torna-se inconsistente fazer alusão aos setores econômicos tradicionais, ou seja, agricultura, indústria e serviços, de forma isolada e desvencilhada, pois tais atividades se interpenetram nesse processo.

Além do mais, a incorporação de formas flexíveis e terceirizadas de trabalho deixa de ser uma estratégia adotada somente no setor industrial, bancário e agricultura, passando também a incorporar o setor público em todas as esferas (federal, estadual, distrital e/ou municipal) e áreas como educação, saúde, comunicação, previdência social, dentre outras.

Tendo como base desse debate o processo de "liofilização organizacional", resultante da eliminação e/ou substituição do trabalho vivo por trabalho morto, conforme afirma Antunes (1999), o mundo do trabalho adentra o século XXI redimensionado, diante dos contornos assumidos e que rebatem diretamente nas condições de vida dos trabalhadores, incidindo nas manifestações da questão social.

A reestruturação produtiva provoca a precarização das relações de trabalho ao estabelecer a flexibilização dos contratos, o que se reflete nas condições degradantes de trabalho e estimula a informalidade. Nesse aspecto, intensificaram-se os trabalhos temporários, parciais, subcontratados e domiciliares, sendo em sua maioria ocupados por mulheres que assumem atividades com baixas remunerações, reforçando e preservando a divisão sexual do trabalho.

O mundo do trabalho revela-se profundamente estratificado, pois "[...] características pessoais dos empregados e sua adequação ao trabalho transforma traços como aparência, idade, educação, gênero e raça em potencial produtivo, de tal forma que características e competências individuais são a condição mesma da empregabilidade" (Sorj, 2000, p. 30).

A partir desse cenário caracterizado por um capitalismo sem fronteiras, cabe enfatizar, de acordo com o que foi abordado, que os desdobramentos das diretrizes econômicas, políticas e ideológicas adotadas a partir da segunda metade do século XX refletiram de forma significativa nos 
direcionamentos da sociedade, sobretudo no mundo do trabalho e nas relações sociais de gênero, pois o que se constata no âmbito da divisão social e sexual do trabalho é um aumento significativo do contingente feminino na esfera da produção, em especial em formas intensivas, desregulamentadas e precarizadas, gerando uma feminização em formas precárias de trabalho que se reflete, também, em uma feminização da pobreza, tendo em vista as condições de pauperismo desse conjunto da população.

A repercussão de todos esses acontecimentos traz, para o contexto das duas primeiras décadas do século XXI, dentre uma de suas resultantes, a erosão do trabalho em seu formato regulamentado e contratado, que passa a ser substituído pelo trabalho temporário, terceirizado, precário, subcontratado e sem garantias legais. A ordem burguesa, com o objetivo estratégico de sustentar um projeto de classe, visa enfraquecer todas as formas de resistência e rebeldias dos trabalhadores, colocando inúmeros desafios para a classe trabalhadora na atualidade.

Vale ressaltar que essa classe trabalhadora de hoje não se restringe ao operário fabril. Esse conjunto de trabalhadores se apresenta na atualidade de forma multifacetada, complexa e heterogênea, o que Antunes (1999) denomina de classe que vive do trabalho.

No bojo dessas consequências produzidas em decorrência das mudanças na relação entre Estado, sociedade e mercado, algumas estratégias são criadas como forma de amenizar as múltiplas expressões da questão social. Dentre elas destacam-se as políticas sociais, que de forma compensatória, focalizada e minimalista, não alteram a estrutura social, ou seja, não incidem na raiz da questão social e não alteram o fosso histórico das desigualdades sociais. No Brasil, em tempos de regressão e erosão dos direitos sociais, merece destaque a expansão dos programas de transferência de renda, em especial a partir do governo de Luís Inácio Lula da Silva (2003-2010), sendo o Programa Bolsa Família (PBF) aquele que assume maior dimensão, repercussão e abrangência. Tal programa, com o objetivo de redução e combate à pobreza da população brasileira, estabelece condicionalidades, o que implica restrição e formas de seletividade para seu acesso. Ou seja, na sociabilidade capitalista não há a plena universalização dos direitos sociais. Os programas governamentais e as políticas sociais podem, reconhecidas suas limitações, amenizar a pobreza e as desigualdades por meio de ações pautadas na redistribuição de renda e da riqueza produzida, porém não alteram na sua essencialidade e substancialidade a estrutura de classes assentada num modo de produção desigual, baseado na sustentação da propriedade privada.

Diante disso, compreendendo a questão social para além da desigualdade social e da pobreza historicamente produzida, mas também como banalização do humano, diante das indiferenças, Iamamoto (2007) pondera que, na contemporaneidade, as refrações da questão social acirram as contradições sociais, contribuindo para a potencialização das lutas coletivas da classe trabalhadora.

\section{Comentários finais}

Ao problematizar as transformações societárias em curso que não alteraram a essencialidade do capitalismo mundial, Antunes (1999; 2005; 2007), destaca que é imprescindível conhecer a atual morfologia do trabalho e as engrenagens complexas do sistema metabólico do capital, para que se possa pensar em um desenho das formas representativas das forças sociais do trabalho diante da precarização, do acentuado desemprego e do pauperismo da população que vive do trabalho.

Nesse cenário de reorganização capitalista e adesão às prerrogativas neoliberais, o que se observa recentemente, com base nas ponderações de Mészáros (2009, p. 17), é uma crise estrutural do capital em sua lógica destrutiva, que assola o mundo das finanças globais e todas as dimensões da vida em sociedade, seja na esfera econômica, cultural ou social. Nesse ínterim, o autor exemplifica a crise bancária ocorrida no decorrer dos anos 2008-2009 e que foi resolvida 
com a injeção de elevadas somas de dinheiro público. Tudo isso em prol de uma boa causa, ou seja, "salvar o sistema". ${ }^{14}$

Não obstante, "[...] os problemas não se esgotam de modo algum no perigoso estado do setor financeiro. [...] também os setores produtivos da indústria capitalista estão com sérios problemas" (Mészáros, 2009, p. 23).

O autor retrata que no auge da consolidação do capitalismo produz-se uma crise alimentar global que atinge grandes contingentes da população do planeta. Como consequência da crise estrutural do capital, aprofunda-se o desemprego e a miséria da humanidade, sendo ilusório esperar uma solução pacífica, feliz e harmoniosa para os tensionamentos evidentes da questão social. A grande preocupação, nessa lógica destrutiva do sistema, é o potencial de autodestruição da humanidade em decorrência dos interesses do capital. Para Mészáros (2009, p. 75) não há dúvidas de que o mundo atual está imerso em uma crise e, para sua superação, surge a necessidade de se reexaminar as condições objetivas das potencialidades históricas para avançar para além do capital, ou seja, buscar uma "nova forma histórica" a partir da "[...] direção de uma transformação sócio-histórica global, cujo objetivo não pode ser outro senão ir para além do capital em sua totalidade" (Mészáros, 2009, p. 78).

Essa realidade apresentada requer enfrentamentos coletivos e compromissos políticos diante do aprofundamento e da agudização da questão social, que se expressam de várias formas, como nas elevadas taxas de desemprego estrutural, informalidade, desproteção social e trabalhista, intensificação das relações laborais (polivalência, extensas jornadas de trabalho, estabelecimento de metas inatingíveis, etc.), terceirização, alta rotatividade no emprego, baixos níveis de rendimento, assédio moral, ameaças e inseguranças no trabalho, crescimento dos acidentes de trabalho, adoecimento físico e mental dos trabalhadores diante da sobrecarga e pressão laboral, fragilização das organizações e lutas coletivas dos trabalhadores no auge da ofensiva neoliberal, analfabetismo, miserabilidade, violência urbana e rural, persistência do trabalho infantil e de formas de trabalho escravo, conforme denúncias publicizadas pelos meios de comunicação, pelo Ministério do Trabalho e Emprego (MTE) e pelo Ministério Público do Trabalho (MPT), racismo e homofobia institucional, xenofobia, crise ecológica, segregação territorial, desigualdade e discriminação no que tange às mulheres, aos negros, aos jovens e aos idosos, perpetuando uma divisão sexual, racial e geracional do trabalho.

Diante deste quadro esboçado, verifica-se a necessidade de compreender os processos sociais em suas contradições, dinamicidade e complexidade para que seja possível pensar e propor alternativas ao modelo societário vigente, tendo em vista a construção de uma forma histórica em que seja possível a plena realização da liberdade, da igualdade, da democracia e da justiça.

\section{Referências}

Alves, G. (2005). O novo (e precário) mundo do trabalho: reestruturação produtiva e crise do sindicalismo. São Paulo: Boitempo.

Anderson, P. (2008). Balanço do neoliberalismo. In: P. Gentili \& E. Sader (Org.). Pós-neoliberalismo: as políticas sociais e o Estado democrático (8.ed.). São Paulo: Paz e Terra.

14 Isso já havia sido elucidado por Chesnais, pois o Estado continua fazendo suas intervenções nos momentos de crise e com o objetivo de garantir a regulação do capital. Segundo o autor, "Não se deve confundir o início de desmantelamento do Estado previdenciário, ou seja, das conquistas democráticas de tipo social em matéria de legislação trabalhista, saúde, assistência social e ensino público, com o desaparecimento, nos países da OCDE, da intervenção estatal no campo das relações econômicas internacionais e na sustentação à competitividade das companhias, mediante instrumentos de política industrial e sobretudo tecnológica" (Chesnais, 1996, p. 234). 
Antunes, R. (2007). Adeus ao trabalho?: ensaios sobre as metamorfoses e a centralidade do mundo do trabalho (12.ed.). São Paulo: Cortez.

Antunes, R. (2005). O caracol e sua concha: ensaios sobre a nova morfologia do trabalho. São Paulo: Boitempo.

Antunes, R. (1999). Os sentidos do trabalho: ensaio sobre a afirmação e a negação do trabalho (3.ed.). São Paulo: Boitempo.

Batista, P. N. (2001). O Consenso de Washington: a visão neoliberal dos problemas latino-americanos (3.ed.). São Paulo: Cartilha Popular.

Chesnais, F. (1996). A mundialização do capital. São Paulo: Xamã.

De Masi, D. (2000). O ócio criativo (3.ed). Rio de Janeiro: Sextante.

Fukuyama, F. (1992). O fim da história e o último homem. Rio de Janeiro: Rocco.

Gorz, A. (1987). Adeus ao proletariado: para além do socialismo. Rio de Janeiro: Forense-Universitária.

Habermas, J. (1987). Técnica e ciência como ideologia. Lisboa: Edições 70.

Harvey, D. (1998). Condição pós-moderna (7.ed.). São Paulo: Loyola.

Harvey, D. (2009). O novo imperialismo (3.ed.). São Paulo: Loyola.

Heller, A. (1985). O Cotidiano e a história (2.ed.). Rio de Janeiro: Paz e Terra.

Hirata, H. (2002). Nova divisão sexual do trabalho? Um olhar voltado para a empresa e a sociedade. São Paulo: Boitempo.

Iamamoto, M. V. (2007). Serviço Social em tempo de capital fetiche: capital financeiro, trabalho e questão social. São Paulo: Cortez.

Ianni, O. (2004). A Idéia de Brasil Moderno. São Paulo: Brasiliense.

Lavinas, L. (2000). Evolução do desemprego feminino nas áreas metropolitanas. In: Maria I. B. da Rocha (Org.). Trabalho e gênero: mudanças, permanências e desafios. Campinas: ABEP:NEPO:UNICAMP, Ed. 34.

Marx, K. (2006). O capital: crítica da economia política. Tradução de Reginaldo Sant’Anna. Livro I, v.1. 23.ed. Rio de Janeiro: Civilização Brasileira.

Mészáros, I. (2009). A crise estrutural do capital. São Paulo: Boitempo.

Offe, C. (1994). Capitalismo desorganizado: transformações contemporâneas do trabalho e da política (2.ed.). São Paulo: Brasiliense.

Pinto, G. A. (2007). A organização do trabalho no século 20: Taylorismo, Fordismo e Toyotismo. São Paulo: Expressão Popular.

Pochmann, M. (2001). O emprego na globalização: a nova divisão internacional do trabalho e os caminhos que o Brasil escolheu. São Paulo: Boitempo.

Ramalho, J. R. \& Santana, M. A. (Org.). (2003). Além da fábrica: trabalhadores, sindicatos e a nova questão social. São Paulo: Boitempo.

Rifkin, J. (1995). O fim dos empregos: o declínio dos níveis dos empregos e a redução da força global de trabalho. São Paulo: Makron Books.

Santana, M. A. (2005). O mundo do trabalho em mutação: as reconfigurações e seus impactos. Cadernos IHU Idéias, 3(34), 1-22. São Leopoldo.

Santos, J. S. (2012). Questão Social: particularidades no Brasil (1ª ed.). São Paulo: Cortez.

Sorj, B. (2000). Sociologia e trabalho: mutações, encontros e desencontros. Revista Brasileira de Ciências Sociais, 15 (43), 25-34. São Paulo.

Vainer, C. (2013). Quando a cidade vai às ruas. In: Cidades rebeldes: Passe Livre e as manifestações que tomaram as ruas do Brasil. São Paulo: Boitempo: Carta Maior.

Endereço para correspondência

E-mail: reginaldog@unb.br
Recebido em: 06/05/2013

Aprovado em: 31/01/2014 